\title{
Involvement of Cyclic AMP in Vasodilatation by Amrinone: A Comparative Study with 3-Isobutyl-1-Methyl-Xanthine (IBMX)
}

\author{
Yukio KISHI and Fujio NUMANO \\ Department of Internal Medicine (3). Faculty of Medicine, Tokyo Medical \\ and Dental University. Bunkyo-ku, Tokyo 113, Japan \\ Accepted September 1, 1986
}

\begin{abstract}
We investigated the effect of amrinone, a non-glycosidic, non-adrenergic cardiotonic drug, on rabbit aortic strips and vascular smooth muscle cells cultured from rabbit aorta. Amrinone relaxed the strips precontracted by $\mathrm{KCl}$, norepinephrine, serotonin or STA $\mathrm{S}_{2}$ in a dose-dependent manner. and it shifted the dose-response curves downward. A similar mode of relaxation was noted with IBMX, an inhibitor of cyclic AMP phosphodiesterase (CAMPPDE). Although propranolol did not affect the relaxation induced by amrinone, $W-7$, a calmodulin antagonist, slightly potentiated and IBMX attenuated the response. In intact smooth muscle cells in culture, amrinone increased basal levels of cAMP and markedly potentiated cAMP accumulation in response to $10^{-6} \mathrm{M}$ isoproterenol. The effect on cAMP accumulation mimicked that of IBMX but the effects were not additive. Inhibition of CAMPPDE was also demonstrated in a cell-free system. IC50 values for amrinone and IBMX being $2.1 \times 10^{-5} \mathrm{M}$ and $1.2 \times 10^{-6} \mathrm{M}$, respectively, using a preparation of CAMPPDE partially purified from the cells by DEAE cellulose chromatography. Amrinone seems to exert a direct effect on vascular smooth muscle cells by potently inhibiting CAMPPDE. This inhibition would to some extent explain the vasodilatory property.
\end{abstract}

Amrinone is a positive inotropic agent which favorably alters hemodynamics in patients with congestive heart failure (1-6). Along with its inotropic action, the vasodilatory property of amrinone may contribute to the increase in cardiac output in these patients $(1,2,6)$. Although the mechanism of inotropic action of the agent has been widely discussed (7-10), factors related to the properties of vasodilatation are poorly understood.

The aim of the present study was to investigate the effect of amrinone on CAMP metabolism in vascular smooth muscle cells in relation to vasodilatation. Firstly. we characterized the mode of amrinone-induced vasodilatation by monitoring the isometric tension of rabbit aortic strips in response to various agonists. The vasodilatory effect was compared with that of IBMX. Secondly, we used cultured smooth muscle cells from rabbit aorta to investigate the involvement of cAMP metabolism in the mechanism of vasodilatation induced by amrinone or IBMX. Our results suggested that CAMP phosphodiesterase (CAMPPDE) inhibition in the smooth muscle cells is involved in the mechanism of the vasodilatory property of amrinone. This is in accord with findings in cardiac muscle cells that the inhibition of this enzyme was responsible for its positive inotropism (10).

\section{Materials and Methods}

Experiments using strips of the rabbit aorta

Eighteen male albino rabbits aged 4-6 months weighing $2.8 \pm 0.1 \mathrm{~kg}$ (Mean \pm S.D.) were used. The thoracic aorta was quickly removed, and six helically cut strips of $2.5 \mathrm{~cm} \times 0.5 \mathrm{~cm}$ were prepared from each aorta. After removing the adventitia using fine scissors, the strips were fixed vertically between hooks under a resting tension of $5 \mathrm{~g}$ in a $40 \mathrm{ml}$ organ bath containing Hanks' solution (137 $\mathrm{mM} \mathrm{Na}^{+}, 5.7 \mathrm{mM} \mathrm{K}+, 0.9 \mathrm{mM}$ 
$\mathrm{Mg}^{2+}, 1.3 \mathrm{mM} \mathrm{Ca}{ }^{2+}, 145.8 \mathrm{mM} \mathrm{Cl}^{-}, 27.4$ $\mathrm{mM} \mathrm{HCO}_{3}^{-}, 0.4 \mathrm{mM} \mathrm{HPO}_{4}^{-}$and $5.6 \mathrm{mM}$ glucose: Nissui Pharmaceutical Co. Tokyo). maintained at $37^{\circ} \mathrm{C}$ and aerated with a mixture of $95 \% \mathrm{O}_{2}$ and $5 \% \quad \mathrm{CO}_{2}(\mathrm{pH} 7.2-$ 7.4). Hooks anchoring the upper end of the strips were connected to the lever of a force displacement transducer (FD pick-up TB 611T. Nihon Kohden Co., Tokyo), and the isometric tension developed was recorded on an ink-writing oscillograph (WI 640G, Nihon Kohden Co., Tokyo), as previously described (11-13).

Vasodilatory properties of amrinone were characterized by its effect on the tension of the strips precontracted by the following agonists: $\mathrm{KCl}$, norepinephrine, serotonin or STA $_{2}$ (9.11-epithio-11,12-methano-TXA $A_{2}$ : a stable thromboxane $A_{2}$ analogue). Contractions induced by these agonists reached a peak and maintained a plateau for a period long enough to observe the effect of the relaxant. Relaxation by amrinone was expressed as percentage of the maximum relaxation induced by $10^{-4} \mathrm{M}$ papaverine (11). Cumulative dose-response curves of the agonists $(\mathrm{KCl}$, norepinephrine, serotonin, angiotensin (I) were obtained in the presence of varying concentrations of amrinone or IBMX added $20 \mathrm{~min}$ prior to the application of the agonists. The concentration of each relaxant for $50 \%$ inhibition of maximum contraction (IC50 values) by the agonists was estimated from a plot of percent inhibition of contraction vs. log concentration of the relaxant. Synergism of amrinone with the other muscle relaxants, propranolol, $N$ (6-aminohexyl)-5-chloro-1 -naphthalenesulfonamide (W-7) and IBMX. was also investigated by determining the effects of pretreatment of these relaxants on amrinoneinduced relaxation of the strips precontracted by $20 \mathrm{mM} \mathrm{KCl}$. Phentolamine, $10^{-6} \mathrm{M}$, was applied 20 min prior to the treatment with $\mathrm{W}-7$ (See Discussion.).

\section{Experiments using cultured vascular smooth muscle cells}

Vascular smooth muscle cells from rabbit aorta were cultured according to the method of Ross (14). The cells were grown in Dulbecco's modified Eagle's medium (DMEM. GIBCO) supplemented with 10\%
(V/V) fetal bovine serum (FBS, GIBCO) with the addition of penicillin $(100 \mathrm{IU} / \mathrm{ml})$ and streptomycin $(100 / \mathrm{g} / \mathrm{ml})$ (GIBCO). The medium was changed twice a week, and the cells which had undergone fewer than 10 passages were used for the following studies

1) Effect of amrinone on cAMP accumulation in intact cells: Effect of amrinone on CAMP accumulation in the cultured smooth muscle cells was investigated using the adenine prelabeling method (15-17). The cells, grown to confluence in a $60 \times 15$ $\mathrm{mm}$ plastic dish (Falcon 3002), were incubated at $37^{\circ} \mathrm{C}$ in DMEM with $\left[{ }^{3} \mathrm{H}\right]$ adenine at the concentration of $0.2 \mu \mathrm{M}(2.2$ $\mu \mathrm{Ci} /$ dish) for $3 \mathrm{hr}$. Incorporation of $\left[{ }^{3} \mathrm{H}\right]$ adenine reached a peak in $3 \mathrm{hr}$, and a plateau was maintained for at least $1 \mathrm{hr}$ (peak values: $65.91 \pm 7.61 \%$, Mean \pm S.D.; $N=10$ ) (17). The labeled cells were rinsed with $3 \mathrm{ml}$ of $0.9 \%$ saline four times to remove the unincorporated $\left[{ }^{3} \mathrm{H}\right]$ adenine. Cyclic AMP accumulation in the cells in response to amrinone was studied in terms of the time course, dose-responsiveness and effects of /-isoproterenol. Incubations were terminated by aspirating off the media and adding $1 \mathrm{ml}$ of ice-cold $0.4 \mathrm{M}$ perchloric acid. The cells were then harvested by scraping with a rubber policeman. sonicated for 20 sec with a "low" setting of 50 on a Ohtake sonicator (Ohtake Co. Ltd., Japan), and centrifuged at $3,000 \mathrm{~g}$ for $10 \mathrm{~min}$. CAMP in the cells was isolated by applying an aliquot of the supernatant to the AG 50WX-4 column followed by a neutral alumina oxide column, as described by Salomon (18). Recovery of the columns was monitored by addition of $\left[{ }^{14} \mathrm{C}\right] \mathrm{CAMP}$ (2,500 dpm/sample) before application to the column. The usual recoveries of $\left[{ }^{14} \mathrm{C}\right]$ CAMP after alumina were 65-75\%.

Radioactivities were determined by a Packard Tri-carb 460 CD. CAMP accumulation in the cells was expressed as radioactivity of $\left[{ }^{3} \mathrm{H}\right] \mathrm{CAMP}$ relative to that of the total $\left[{ }^{3} \mathrm{H}\right]$ adenine incorporated into the cells (\% conversion) (16).

2) Effect of amrinone on CAMPPDE activity: CAMPPDE of the homogenates of the smooth muscle cells were partially purified by DEAE cellulose chromatography $(19,20)$. The cells grown to confluence in a 
$75 \mathrm{~cm}^{2}$ flask (Corning) were harvested by a rubber policeman. resuspended in homogenizing buffer (10 $\mathrm{mM}$ Tris/Cl. $\mathrm{pH}$ 8.0; $50 \mathrm{mM}$ NaF, $20 \mu \mathrm{M} \quad \mathrm{N}$-p-tosyl-L-lysine chloromethyl ketone (TLCK); $20 \mu \mathrm{M}$ leupeptin and $1 \%$ Triton $x-100$ (V/V)) and homogenized in a glass homogenizer with a Teflon pestle using 10 strokes by hand at $0^{\circ} \mathrm{C}$. After centrifugation $(40.000 \mathrm{~g} .30 \mathrm{~min}$ at $4^{\circ} \mathrm{C}$ ), the supernatant was applied to a small column $(5.5 \times 100 \mathrm{~mm})$ containing about $1.0 \mathrm{ml}$ of DE 52 equilibrated with 15 $\mathrm{mM}$ sodium acetate. $5 \mathrm{mM} 2$ - ( $\mathrm{N}$-morpholino) ethane-sulfonic acid (MES), 30\% ethylene glycol (V/V). $0.1 \mathrm{mM}$ dithiothreitol (DTT), $10 \mu \mathrm{M}$ TLCK, $10 \mu \mathrm{M}$ leupeptin. The column was washed by 3 bed volumes of equilibrating buffer and further washed by 5 bed volumes of the buffer with a sodium acetate concentration of $200 \mathrm{mM}$. CAMPPDE was eluted with $1.5 \mathrm{ml}$ of the buffer with a sodium acetate concentration of $500 \mathrm{mM}$. This eluate contained about $50 \%$ the total PDE activity and was used as the partially purified "low $\mathrm{K}_{\mathrm{m}}$ " CAMPPDE. The activity of CAMPPDE was assayed with the substrate concentration of $0.25 \mu \mathrm{M}$ according to Thompson and Appleman (21). The IC50 value of amrinone and $I B M X$ required to inhibit CAMPPDE was estimated from a plot of percent inhibition of the enzyme activity vs. log concentration of amrinone. Tissue protein was measured by the method of Lowry et al. (22) with human serum albumin as a standard.

\section{Reagents}

$\left[2,8-{ }^{3} \mathrm{H}\right]$ adenine (specific activity: 14.7 $\mathrm{Ci} / \mathrm{mmol}),\left[2.8-{ }^{3} \mathrm{H}\right]$ CAMP $(31.5 \mathrm{Ci} / \mathrm{mmol})$, $\left[8-{ }^{14} \mathrm{C}\right]$ cAMP $(51.4 \mathrm{mCi} / \mathrm{mmol})$ were purchased from New England Nuclear. The following materials were purchased: $A G 50$ WX-4 (Bio-Rad), neutral alumina oxide (Merck), DE 52 (Whatman), /-isoproterenol, d,I-propranolol. Tris, NaF, leupeptin, TLCK. IBMX, DTT (Sigma). phentolamine. $\mathrm{HCl}$ (Ciba). Triton $X-100$ (Kanto Kagaku, Japan), STA $_{2}$ (Ono Yakuhin, Japan). W-7 (Seikagaku Kogyo, Japan). Amrinone was a generous gift from Prof. S. Shibata of Hawaii University. U.S.A. All the other reagents were of the best grades available and were not purified further.

\section{Results}

Amrinone-induced relaxation of rabbit aortic strips: Amrinone elicited a dosedependent relaxation of the aortic strips precontracted by all the agonists tested, as shown in Fig. 1. Amrinone at $4 \times 10^{-4} \mathrm{M}$ relaxed the strips exposed to $20 \mathrm{mM} \mathrm{KCl}$. $5 \times 10^{-7} \mathrm{M}$ norepinephrine, $10^{-6} \mathrm{M}$ serotonin and $10^{-7} \mathrm{M} \mathrm{STA}_{2}$ by $57.9 \%, 88.9 \%, 84.9 \%$ and $26.7 \%$, respectively (Values are the means of triplicate determinations).

Preincubation with amrinone for $20 \mathrm{~min}$ before application of the agonists shifted the dose-response curves for $\mathrm{KCl}$, norepinephrine, serotonin or angiotensin II significantly downward and slightly to the right (Fig. 2). Contractions by angiotensin II were most susceptible to amrinone followed by serotonin, norepinephrine and $\mathrm{KCl}$. IC50 values of amrinone for inhibition of maximal
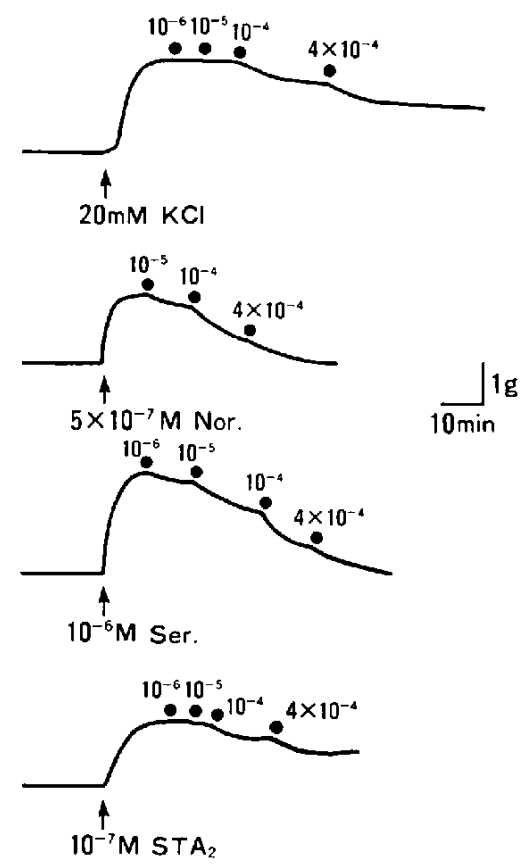

Fig. 1. Relaxing effect of amrinone on contractions induced by agonists. Following a 2 he equilibration period, the vasocontracting agents were added to the medium (arrows). After the contraction reached a plateau, amrinone was applied cumulatively (dots). Finally, $10^{-4} \mathrm{M}$ papaverine was applied to obtain maximum relaxation (11). 
contraction by $\mathrm{KCl}$, norepinephrine, serotonin and angiotensin II were calculated to be $>10^{-3} \mathrm{M} .5 .2 \times 10^{-4} \mathrm{M} .7 .3 \times 10^{-5} \mathrm{M}$ and $2.9 \times 10^{-5} \mathrm{M}$. respectively. Similarly. IBMX shifted the dose-response curves downward (Fig. 3), although IBMX proved to be a more potent vasodilator, $1 \mathrm{C} 50$ values being $6.4 \times 10^{-4} \mathrm{M}, 4.0 \times 10^{-5} \mathrm{M}, 2.8 \times 10^{-5} \mathrm{M}$ and $1.1 \times 10^{-5} \mathrm{M}$, respectively (Values are derived from 4-6 separate experiments).

Effects of pretreatment with propranolol, W-7 or IBMX on amrinone-induced relaxation are shown in Fig. 4. As compared with the control tracings, propranolol had no effect, and $W-7$ slightly potentiated the relaxation by amrinone. Pretreatment with $I B M X$, however, appeared to attenuate the response, although both $W-7$ and IBMX
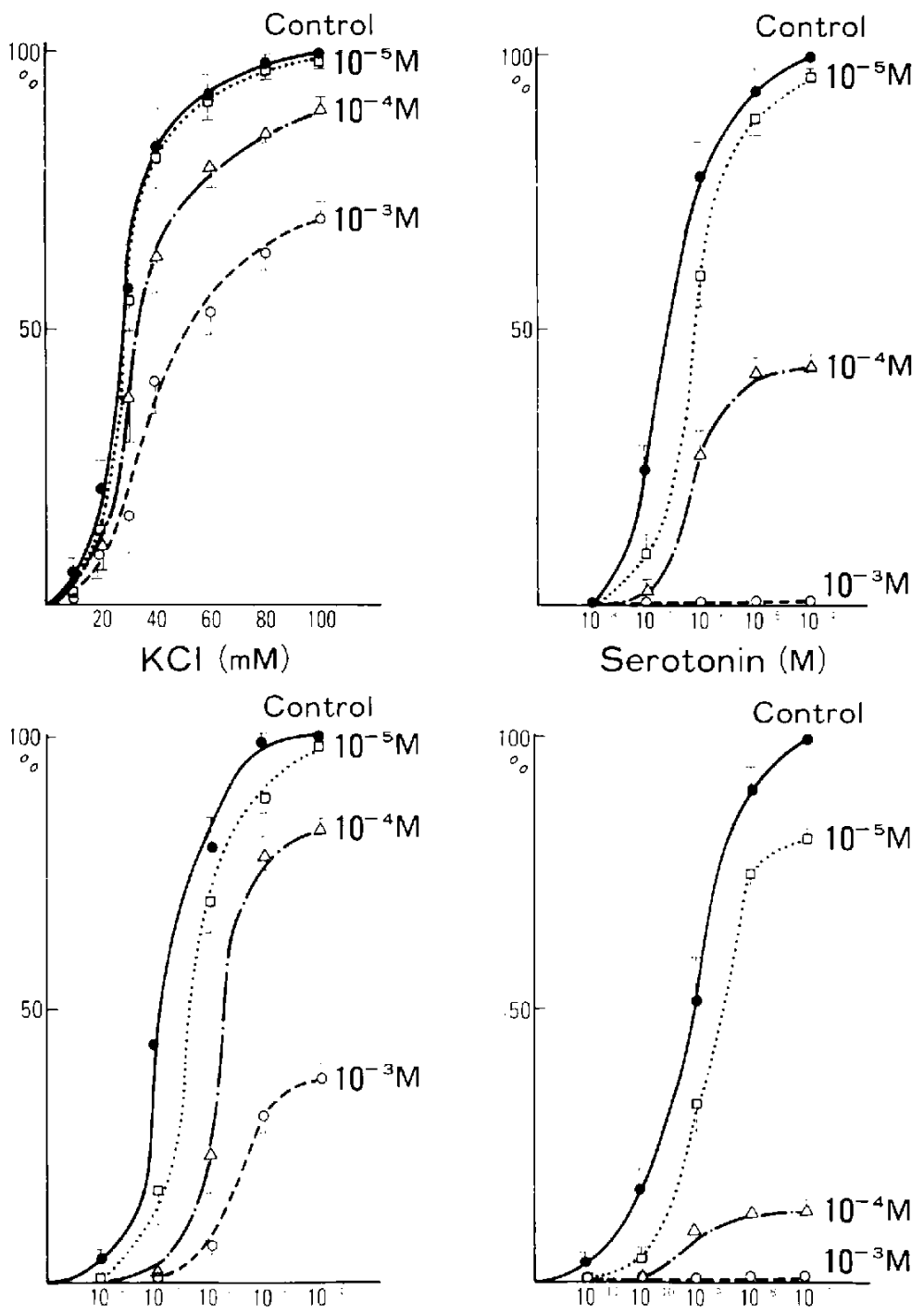

Norepinephrine (M)

Fig. 2. Effect of amrinone on dose-response curves of the agonists. The strips were treated with $10^{-5}$ $10^{-3} \mathrm{M}$ amrinone for $20 \mathrm{~min}$, and the agonists were applied cumulatively. Maximum contractions by each agonist were taken as $100 \%$. Values are the means \pm S.E.M. of 4-6 experiments. 
inhibited $20 \mathrm{mM} \mathrm{K} \mathrm{K}^{+}$-induced contraction by about $30 \%$.

CAMP accumulation in intact smooth muscle cells in culture: The time course of CAMP accumulation in the cells after application of $10^{-3} \mathrm{M}$ amrinone is shown in Fig. 5. Incubation with amrinone significantly increased the CAMP levels at al! incubation periods, being highest at 1 min, maintaining a plateau after $5 \mathrm{~min}$. The cAMP levels in the cells incubated without amrinone were virtually unchanged throughout. Amrinone induced dose-dependent increase in CAMP accumulation both in the basal levels (Table 1) and in the response to $10^{-6} \mathrm{M}$ isoproterenol (Fig. 6). It is noteworthy that CAMP accumulation in response to isoproterenol was markedly potentiated in the presence of amrinone.

IBMX at $10^{-3} \mathrm{M}$ had a similar effect on
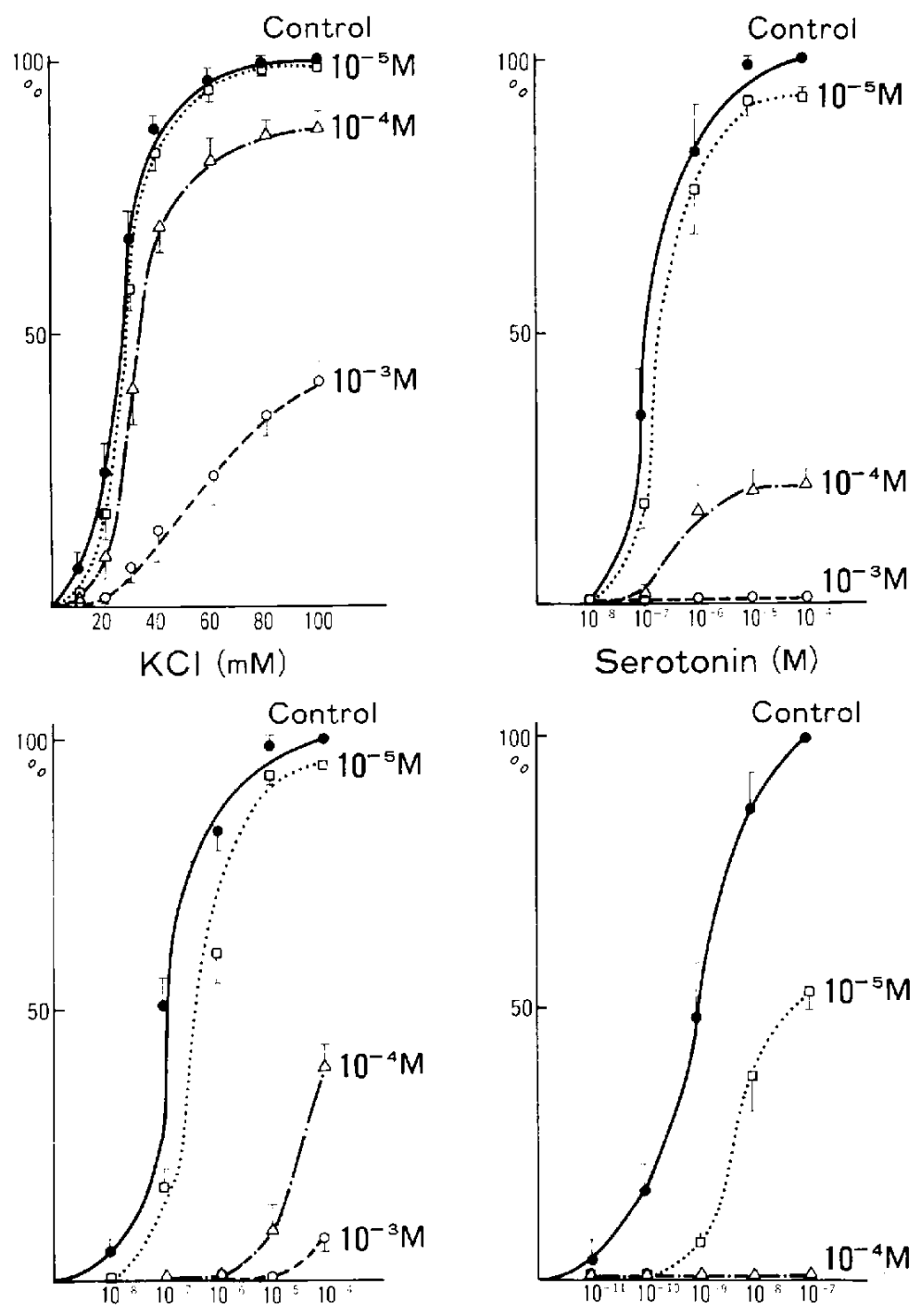

Norepinephrine $(M)$

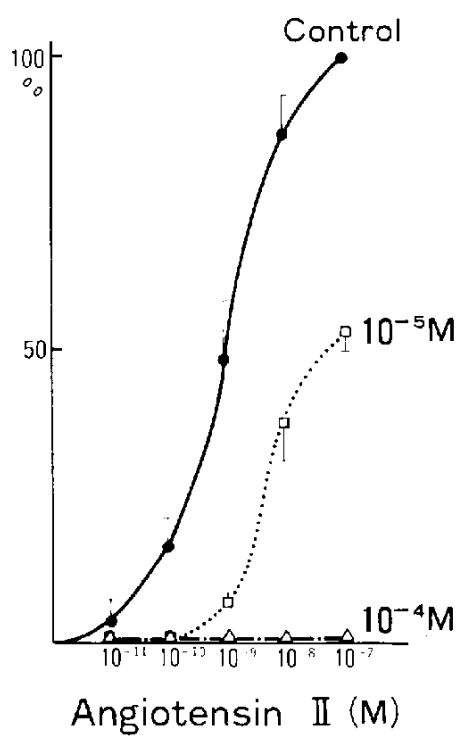

Fig. 3. Effect of IBMX on the dose-response curves of the agonists. The experimental protocol was the same_as in Fig. 2. 
CAMP accumulation, but combined treatment with $10^{-3} \mathrm{M}$ amrinone did not differ significantly in terms of cAMP accumulation (Fig. 7).

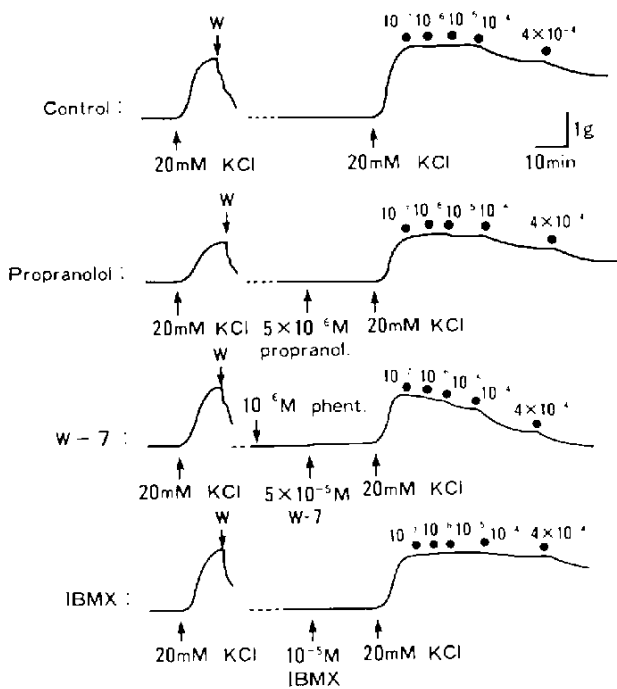

Fig. 4. Effect of pretreatment with propranolol, W-7 or IBMX on amrinone-induced relaxation. These agents were added to the medium $20 \mathrm{~min}$ prior to $\mathrm{KCl}(20 \mathrm{mM})$ application. Phentolamine, $10^{-6} \mathrm{M}$. was applied 20 min prior to the treatment of $\mathrm{W}-7$. After the contraction by $\mathrm{KCl}$ reached a peak, amrinone was applied cumulatively. Each tracing was recorded after $2 \mathrm{hr}$ of equilibration following the control tracing (left side of the panel). Windicates washing of the strip with the medium.

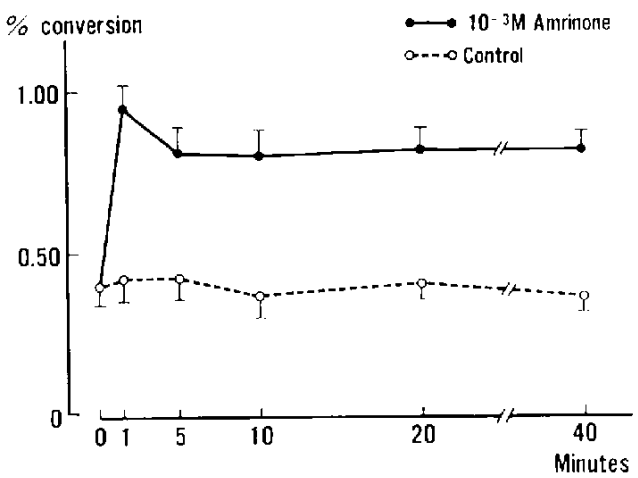

Fig. 5. Time course of cAMP accumulation in the cells incubated in the presence or absence of $10^{-3} \mathrm{M}$ amrinone $(\mathrm{N}=4)$. The $\left[{ }^{3} \mathrm{H}\right]$-labeled cells were rinsed four times with $3 \mathrm{ml}$ of $0.9 \%$ saline and incubated with the medium.
Effect of amrinone on cAMPPDE: The activity of a partially purified preparation of CAMPPDE from the cultured smooth muscle cells was $0.8 \mathrm{nmol} / \mathrm{min} / \mathrm{mg}$ protein, as determined by the substrate concentration of $0.25 \mu \mathrm{M}$. Dose-inhibition curves for amrinone and IBMX are shown in Fig. 8. Amrinone inhibited the enzyme in a dose-dependent manner with an $1 \mathrm{C} 50$ value of $2.1 \times 10^{-5} \mathrm{M}$; and at a concentration of $10^{-3} \mathrm{M}$. complete inhibition was achieved. IBMX also inhibited the enzyme in a similar fashion, but appeared

Table 1. Dose-responsiveness of CAMP accumulation in the cells incubated with amrinone

\begin{tabular}{lc}
\hline Control & cAMP (\% conversion) \\
$10^{-6} \mathrm{M}$ Amrinone & $0.329 \pm 0.017$ \\
$10^{-5} \mathrm{M}$ Amrinone & $0.351 \pm 0.028$ \\
$10^{-4} \mathrm{M}$ Amrinone & $0.365 \pm 0.012$ \\
$10^{-3} \mathrm{M}$ Amrinone & $0.523 \pm 0.029^{*}$ \\
\hline
\end{tabular}

Values are the means \pm S.E.M. of 4 dishes. "Significantly different from the control cells $(P<0.01)$.

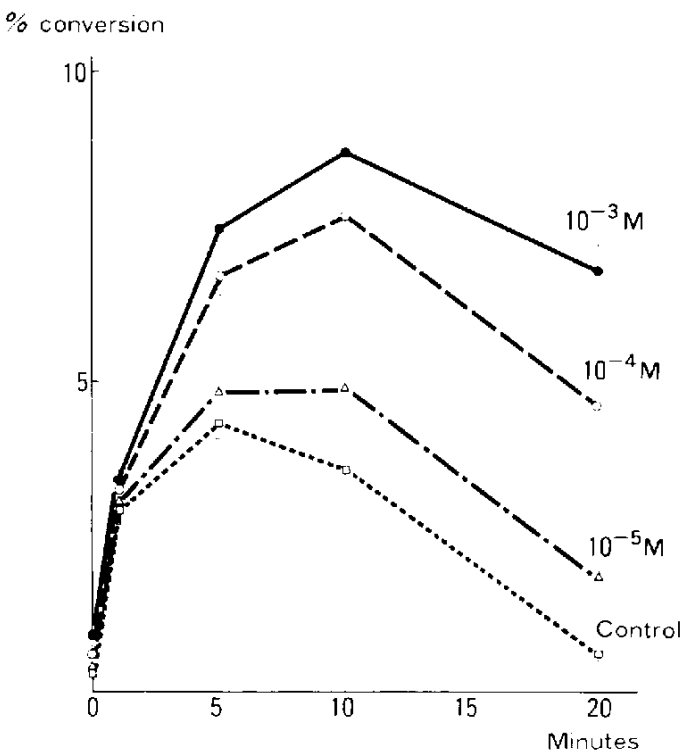

Fig. 6. Effect of amrinone on CAMP accumulation in response to isoproterenol. After preincubation in the absence (control) or presence of amrinone (concentrations indicated) for $20 \mathrm{~min}, 10^{-6} \mathrm{M}$ isoproterenol was applied to the incubation medium at 0 min, and the time course of CAMP accumulation was observed (Mean \pm S.E.M.: $N=4-8$ ). 


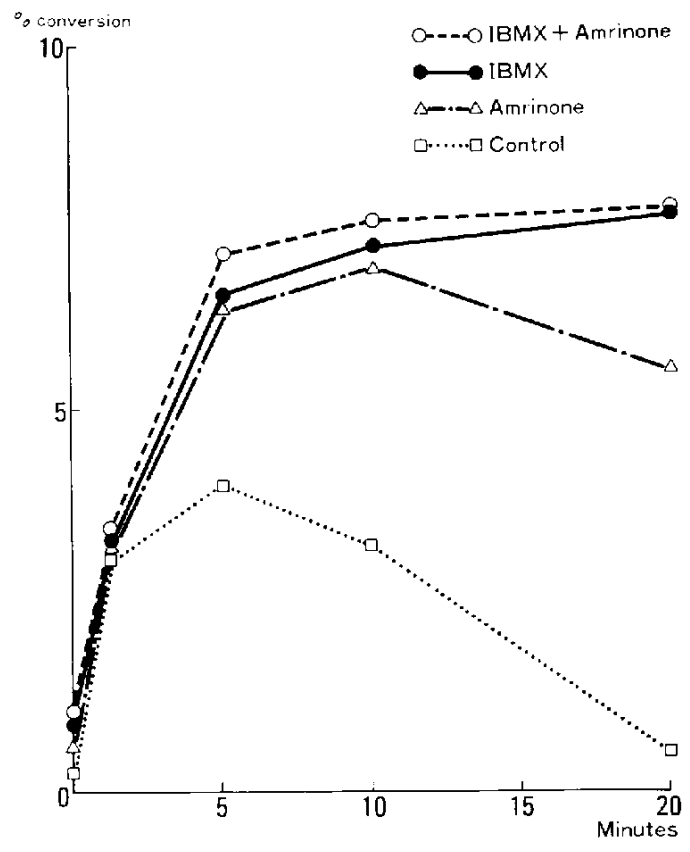

Fig. 7. Effect of IBMX and amrinone on CAMP accumulation and their interaction. The cells were treated with $10^{-3} \mathrm{M}$ amrinone and/or $10^{-3} \mathrm{M}$ IBMX at 20 min prior to application of $10^{-6} \mathrm{M}$ isoproterenol, and CAMP accumulation was compared with the control cells without pretreatment before isoproterenol.

to be more potent than amrinone with an IC50 value of $1.2 \times 10^{-6} \mathrm{M}$.

\section{Discussion}

Meisheri et al. (23) reported that amrinone relaxed rabbit aortic rings precontracted by high $\mathrm{K}^{+}$and norepinephrine and that this drug increased CAMP concentration in the rings. They postulated that the inhibitory effect of amrinone on the contraction appeared to be nonspecific and might be related with CAMP metabolism in the smooth muscle cells. Our results support their conclusion in that amrinone acted as a nonspecific vasodilator which relaxed all the strips precontracted by various contractile agents and shifted the dose-response curves downward and in a dose-dependent manner. A similar mode of relaxation was noted with IBMX.

Effects of $W-7$ and IBMX on relaxation by amrinone (Fig. 4) are of special interest. W-7

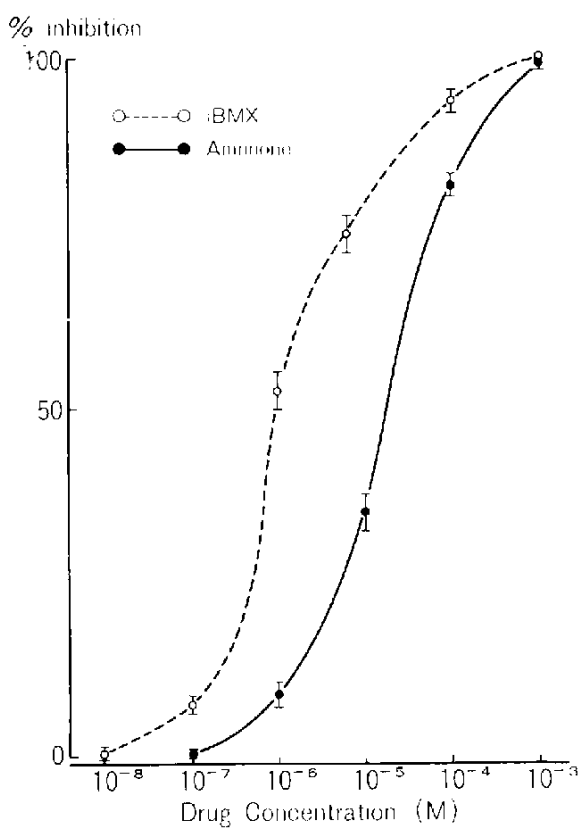

Fig. 8. Inhibition of CAMP PDE activity by amrinone and $\operatorname{IBMX}(\mathrm{N}=3)$.

was confirmed to have at least dual pharmacological actions: calmodulin-related relaxation and calmodulin-independent contraction (24). Since our purpose of using $W-7$ was to compare the mode of relaxation with those of other relaxants, the latter action should be minimized. This was achieved by treating the arterial strip with $10^{-6} \mathrm{M}$ phentolamine at $20 \mathrm{~min}$ prior to the application of amrinone, because the mechanism of calmodulin-independent contraction involved increased efflux of norepinephrine from sympathetic nerve terminals (24). Phentolamine at this concentration did not affect $\mathrm{K}^{+}$-induced contraction or amrinoneinduced relaxation significantly (data not shown). Pretreatment with $5 \times 10^{-5} \mathrm{M} \mathrm{W}-7$ or $10^{-5} \mathrm{M}$ IBMX inhibited $20 \mathrm{mM} \mathrm{K} \mathrm{K}^{+}$-induced contraction of rabbit aorta by $30 \%$, but $\mathrm{W}-7$ enhanced relaxation by amrinone. while IBMX failed to elicit an additive effect. W-7, in addition to the calmodulin-related relaxation, was reported to inhibit CAMPPDE (25). Thus, enhancement of relaxation by $W-7$ could be explained by inhibition of CAMPPDE. However, as noted by Hidaka et al., the IC50 value for inhibiting "low $\mathrm{K}_{\mathrm{m}}$ " 
CAMPPDE, a partially purified preparation from human vascular smooth muscle cells, was $320 \mu \mathrm{M}(25)$. which is much higher than that of IBMX. Therefore, it seems unlikely that inhibition of CAMPPDE by $W-7$ is responsible for the additive effect. Conclusively, it is suggested that $W-7$ enhances relaxation by amrinone probably through interaction with calmodulin and that a common mechanism is involved in the relaxation by amrinone and IBMX.

Our current study using rabbit aortic strips suggested amrinone relaxed the arterial wall probably through direct inhibition of smooth muscle cells, possibly mediated by CAMPPDE inhibition. To further characterize the effect of amrinone on vascular smooth muscle cells, we turned to the cell culture technique, employing smooth muscle cells from rabbit aorta. These cells retained thin and thick filaments, responded to catecholamines as well as phosphodiesterase inhibitors and were found to be a good model system in which to study cAMP metabolism (17). Furthermore, this approach could eliminate some of the heterogeneities inherent to vessel walls such as effects of endothelium, connective tissue or uneven distribution of nervous systems.

We confirmed that $10^{-3} \mathrm{M}$ amrinone increased CAMP levels about 2.5-fold and markedly potentiated cAMP accumulation, in response to $10^{-6} \mathrm{M}$ isoproterenol in cultured smooth muscle cells. Although IBMX had similar effects on CAMP accumulation, the combined treatment added little to the increase in CAMP accumulation at basal levels and in response to isoproterenol. These results again suggested that amrinone, like IBMX, enhanced CAMP accumulation through inhibition of CAMPPDE in intact smooth muscle cells. Amrinone inhibited the partially purified low $K_{m}$ CAMPPDE with an IC50 value of $2.1 \times 10^{-5} \mathrm{M}$. IBMX was a more potent inhibitor with an 1 C50 value of $1.2 \times 10^{-6} \mathrm{M}$. It is noteworthy that IC50 values for inhibition of CAMPPDE by the two relaxants appeared to correlate with those for inhibition of contraction by the agonists. Endoh et al. (10) reported that amrinone enhanced CAMP accumulation in isolated canine ventricular muscle through inhibition of CAMPPDE and that the levels of CAMP in the specimen positively correlated with the inotropism of amrinone. They also showed that amrinone inhibited the partially purified preparation of CAMPPDE with an IC50 value of 3 to $4 \times 10^{-5} \mathrm{M}$. such being similar to the findings in our study. Thus, amrinone may produce concomitantly a positive inotropism and vasodilatation, through a common mechanism: inhibition of CAMPPDE.

Clinical reports revealed that increases in the cardiac index showed a linear relationship to the plasma concentration of amrinone in a range of $0.5 \mu \mathrm{gg} / \mathrm{ml}$ to $7 \mu \mathrm{g} / \mathrm{ml}$, i.e.. $2.7 \times 10^{-6} \mathrm{M}$ to $3.7 \times 10^{-5} \mathrm{M}$. (3), such being comparable with the concentration at which amrinone exhibited a pharmacological action in the present studies. Moreover, it has been shown that amrinone improves hemodynamic indices by vasodilatation with no evidence of a direct effect on contractility in patients with chronic heart failure (26). The amrinoneinduced alteration in CAMP accumulation in vascular smooth muscle cells may play an important role in the therapeutic effects of this agent.

Acknowledgement: We thank M. Ohara for helpful comments on the manuscript.

\section{References}

1 Benotti, J.R., Grossman, W., Braunwald, E., Davolos, D.D. and Alousi, A.A.: Hemodynamic assessment of amrinone. N. Engl. J. Med. 299, 1373-1377 (1978)

2 Le Jemtel, T.H., Keung, E., Sonnenblick, E.H., Ribner, H.S., Matsumoto, M., Davis, R., Schwartz, W., Alousi, A.A. and Davolos, D.: Amrinone: A new non-glycosidic, non-adrenergic cardiotonic agent effective in the treatment of intractable myocardial failure in man. Circulation 59, 10981104 (1979)

3 Edelson, J., Le Jemtel, T.H., Alousi, A.A., Biddlecome, C.E., Maskin, C.S. and Sonnenblick, E.H.: Relationship between amrinone plasma concentration and cardiac index. Clin. Pharmacol. Ther. 29, 723-728 (1981)

4 Weber, K.T., Andrews, V., Janicki, J.S., Wilson, J.R. and Fishman, A.P.: Amrinone and exercise performance in patients with chronic heart failure. Am. J. Cardiol. 48, 164-169 (1981)

5 Maskin, C.S., Forman, R., Klein, N.A., Sonnenblick, E.H. and Le Jemtel, T.H.: Long-term amrinone therapy in patients with severe heart 
failure. Am. J. Med. 72, 113-118 (1982)

6 Mancini, D., Le Jemtel, T. and Sonnenblick, E.: Intravenous use of amrinone for the treatment of the failing heart. Am. J. Cardiol. 56, 8B-15B (1985)

7 Farah, A.E. and Alousi, A.A.: New cardiotonic agents: A search for digitalis substitute. Life Sci. 22, 1139-1148(1978)

8 Onuaguluchi, G. and Tanz, R.D.: Cardiac effects of amrinone on rabbit papillary muscle and guinea pig Langendorff heart preparations. J. Cardiovasc. Pharmacol. 3, 1342-1355 (1981)

9 Horeijäger, P., Schäfer-Korting, M. and Reiter, M.: Involvement of cyclic AMP in the direct inotropic action of amrinone-Biochemical and functional evidence. Naunyn Schmiedebergs Arch. Pharmacol. 318, 112-120 (1981)

10 Endoh, M., Yamashita, S. and Taira, N.: Positive inotropic effect of amrinone in relation to cyclic nucleotide metabolism in the canine ventricular muscle. J. Pharmacol. Exp. Ther. 221, 775-783 (1982)

11 Toda, N., Hojo, M., Sakae, K. and Usui, H.: Comparison of the relaxing effect of dopamine with that of adenosine, isoproterenol and acetylcholine in isolated canine arteries. Blood Vessels 12, 290-301 (1975)

12 Kishi, Y. and Numano, F.: A study on the mechanism of estrogen as an antiatherosclerotic: The inhibitory effect of estrogen on A23187induced contraction of the aortic wall. Mech. Ageing Dev. 18, 115-123 (1982)

13 Kishi, Y. and Numano, F.: Contractions in normal and atherosclerotic rabbit aortas. Mech. Ageing Dev. 26, 357-369 (1984)

14 Ross, R.: The smooth muscle cell II. Growth of smooth muscle cell in culture and formation of elastic fibers. J. Cell Biol. 50, 172-186 (1971)

15 Kuo, J.F. and Renzo, E.C.: A comparison of the effects of lipolytic agents on adenine $3^{\prime}, 5^{\prime}$ monophosphate levels in adipose cells as determined by prior prelabelling with adenine8-14C. J. Biol. Chem. 244, 2250-2260 (1969)

16 Haslam, R.J. and Vanderwel, M.: Inhibition of platelet adenylate cyclase by 1-0-alkyl-2-o- acetyl-sn-glyceryl-3-phosphorylcholine (platelet activating factor). J. Biol. Chem. 257, 68796883 (1982)

17 Kishi, Y., Nishiyama, K. and Numano, F.: Cyclic AMP accumulation in rabbit aorta smooth muscle cells altered in the presence of hyperlipidemic serum. Atherosclerosis 56, 213-222 (1985)

18 Salomon, Y.: Adenylate cyclase assay. Adv. Cyclic Nucleotide Res. 10, 35-55 (1979)

19 Hidaka, H., Yamaki, T., Ochiai, Y., Asano, T. and Yamabe, H.: Cyclic 3',5'-nucleotide phosphodiesterase determined in various human tissues by DEAE-cellulose chromatographyBiochim. Biophys. Acta 484, 398-407 (1977)

20 Thompson, W.J., Epstein, P.M. and Strada, S.J.: Purification and characterization of high affinity cyclic adenosine monophosphate phosphodiesterase from dog kidney. Biochemistry 18, 52285237 (1979)

21 Thompson, W.J. and Appleman, M.H.: Multiple cyclic nucleotide phosphodiesterase activities in rat brain. Biochemistry 10, 311-316 (1971)

22 Lowry, O.H., Rosebrough, N.J., Farr, A.L, and Randall, R.J.: Protein measurement with the Folin phenol reagent. J. Biol. Chem. 193, 265275 (1951)

23 Meisheri, K.D., Palmer, R.F. and Van Breemen, C.: The effects of amrinone on contractility. $\mathrm{Ca}^{++}$ uptake and CAMP in smooth muscle. Eur. J. Pharmacol. 61, 159-165 (1980)

24 Hidaka, H., Asano, M. and Tanaka, T.: Activitystructure relationships of calmodulin antagonists: Naphthalene-sulfonamide derivatives. Mol. Pharmacol. 20, 571-578 (1981)

25 Hidaka, H., Yamaki, T., Asano, M. and Totsuka, $T$ : Involvement of calcium in cyclic nucleotide metabolism in human vascular smooth muscle. Blood Vessels 15, 55-64 (1978)

26 Wilmshurst, P.T., Thompson, D.S., Jenkins, B.S., Coltart, D.J. and Webb-Peploe, M.M.: Haemodynamic effects of intravenous amrinone in patients with impaired left ventricular function. Br. Heart J. 49, 77-82 (1983) 